\title{
Retraction of "Van Ginkel, J. R., \& Kroonenberg, P. M. (2020). Much ado about nothing: Multiple imputation to balance unbalanced designs for two-way analysis of variance"
}

Methodology, 2020, Vol. 16(4), 354-355, https://doi.org/10.5964/meth.6073

Published (VoR): 2021-02-08

The following article has been retracted by agreement between the authors, the Editors-in-Chief (Jost Reinecke, José-Luis Padilla) and the publisher of the journal (Leibniz Institute for Psychology):

Van Ginkel, J. R., \& Kroonenberg, P. M. (2020). Much ado about nothing: Multiple imputation to balance unbalanced designs for two-way analysis of variance. Methodology, 16(4), 335-353. https://doi.org/10.5964/meth.4327

The authors report: "After publication we detected a programming error in the code used to calculated the $\mathrm{D}_{1}$ statistic. When corrected the main conclusions of the article no longer hold. We therefore wish to withdraw the article and apologize for any confusion caused by this error."

The journal's Editors-in-Chief have invited the authors to submit a corrected version of the retracted article which will be re-reviewed and, if accepted, published in a future issue. 


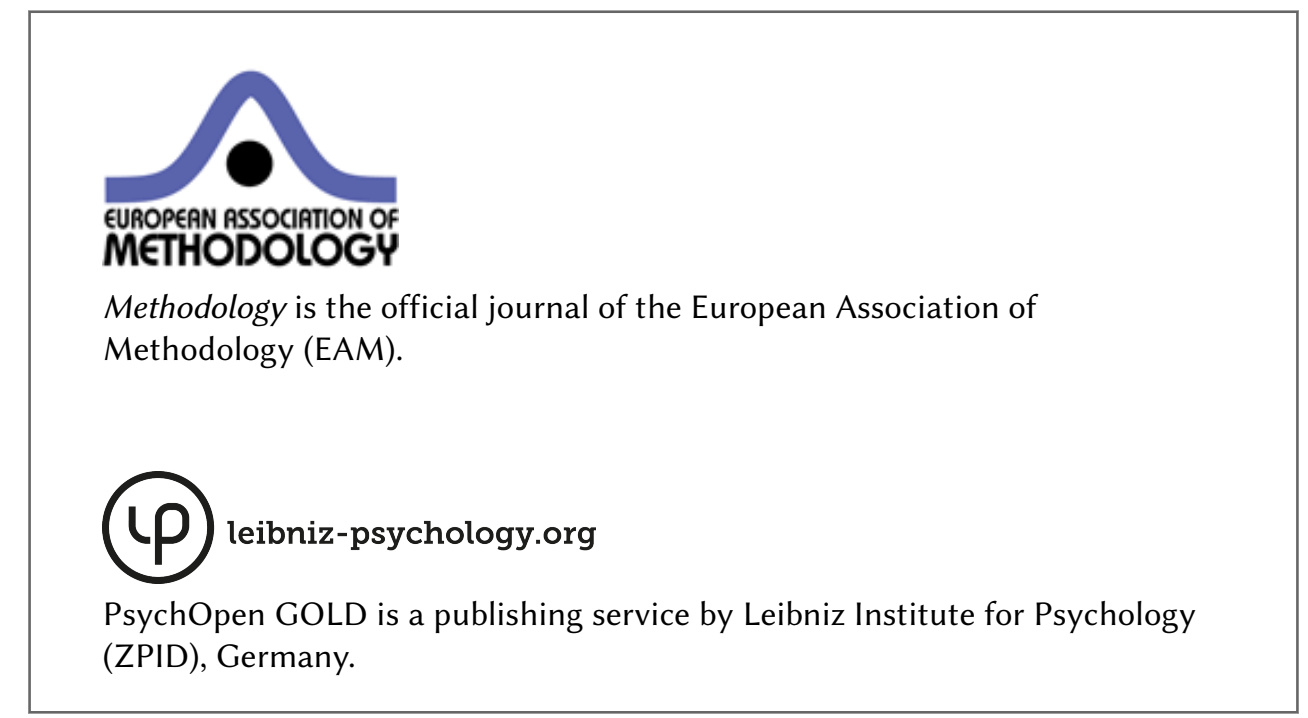

